Polymer Journal, Vol. 3, No. 6, pp 675-680 (1972)

\title{
Manganese(IV)-Initiated Graftcopolymerization of Methyl Methacrylate on Wool Fibers
}

\author{
Abdel-aziz Kantouch, Saleh Abdel-Fattah, and Ali Hebeish \\ National Research Center, Textile Research Laboratory \\ Dokki, Cairo, Egypt.
}

(Received November 20, 1971)

\begin{abstract}
Potassium permanganate-induced graftcopolymerization of methyl methacrylate(MMA) on wool fibers was investigated under a variety of conditions. The graft yield was favourably influenced by increasing the reaction time and monomer and initiator concentration. Raising the reaction temperature from 50 to $70^{\circ} \mathrm{C}$ causes a significant increment in the graft yield. Using 4-mmolar potassium permanganate and 6-\% methyl methacrylate at $\mathrm{pH} 1$ (pH was adjusted by nitric acid), a graft yield of $70 \%$ could be obtained at $70^{\circ} \mathrm{C}$ in two hours reaction time. This yield could be increased up to $180 \%$ if wool is treated with thioglycolic acid prior to grafting. Dinitrophenylated wool, on the other hand, showed a negligible graft yield, indicating that amino and hydroxyl groups in the wool molecules acts as sites for grafting. The consumption of permanganate was so rapid that about $60 \%$ of it was consumed in the first thirty minutes of the reaction during oxidation. On the other hand, relatively shorter time was required to cause full consumption during grafting. The excess of permanganate during grafting over that during oxidation was anticipated to initiation and termination of homopoly (methyl methacrylate). Wool with a graft yield of $c a$. 50\% is nearly insoluble in alkali compared to the untreated one which is nearly completely soluble under similar conditions. A tentative mechanism for grafting on wool induced by permanganate was proposed.

KEY WORDS Permanganate / Graftcopolymerization / Wool / Methyl Methacrylate / Dinitrophenylated Wool / Permanganate / Consumption Mechanism /
\end{abstract}

Grafting of wool with vinyl monomers has gained a considerable interest in the last few years. Literature survey showed that most of the work on such type of grafting involve a radical mechanism. Hence, the primary step entails producing free radical sites on the wool backbone. This may be achieved by a variety of methods, e.g., high-energy radiation ${ }^{1}$, lowenergy radiation in presence or absence of sensitizer $^{2,3}$ and redox system., ${ }^{4,5} \mathrm{~A}$ redox system generates free radicals in the reaction medium which subsequently attack the wool molecules thereby giving rise to free radical sites. Typical example of this is the persulphate-thiosulphate, ${ }^{4}$ and hydrogen peroxide--ferrous ion systems. ${ }^{5}$

Initiation of free radicals capable of inducing grafting onto wool has also been possible by using powerful oxidizing agents which attack wool directly such as ceric ions ${ }^{6,7}$ and periodic acid. $^{8}$ In addition, complex compounds like trichloroacetic acid-bis(acetonylacetonato) copper(II) are able to produce free radicals which are capable of initiating vinyl graftcopolymerization onto wool. ${ }^{9,10}$ Although, a good number of studies have dealt with initiation of homopolymerization of various vinyl monomers by potassium permanganate in acidic medium, only few studies have shown its ability to initiate graftcopolymerization on textile fibers. ${ }^{11,22}$

The present work aims to investigate the feasibility of using potassium permanganate to initiate graftcopolymerization of methyl methacrylate on wool. Changes in the physical and/or chemical characteristics of wool on its susceptibility towards grafting with this initiator was also studied. Furthermore the solubility properties of the grafted samples were examined. 


\section{EXPERIMENTAL}

\section{Materials}

Merino wool fibers were purified by extraction with acetone in a Soxhlet apparatus for about $24 \mathrm{hr}$, followed by washing with cold water and air drying. Commercial methyl methacrylate (MMA) was washed with 5-\% sodium hydroxide and water; it was dried over anhydrous sodium sulphate, and distilled under reduced pressure in nitrogen before use.

Potassium permanganate, thioglycollic acid (TGA), and dinitrofluorobenzene(DNFB) were of A. R. grade.

\section{Chemical Modification of Wool}

Purified wool was subjected to the following chemical reactions.

(1) Reduction. Reduction of wool with $0.2-N$ thioglycollic acid was carried out for $24 \mathrm{hr}$ at $30^{\circ} \mathrm{C}$ using a material to liquor ratio $1: 100 .^{4}$

\section{Graft yield (\%)}

Oxidation of wool with potassium permanganate was carried under conditions identical with those described above, except that methyl methacrylate was absent.

\section{Permanganate Consumption}

The reaction system (wool sample+reaction solution) was treated with an excess of acidified standard sodium oxalate, to reduce any unreacted potassium permanganate and manganese dioxide. The solution is then filtered and backtitrated with a standard $0.1-N$ potassium permanganate solution. The permanganate consumption is then calculated by difference.

\section{Alkali Solubility}

Solubility of wool in $0.1-N$ sodium hydroxide was determined according to the method of Harris. ${ }^{14}$

\section{Cystine and Cysteine Content}

Cystine and cysteine were estimated in the wool hydrolyzate by a modified Shinohara method. ${ }^{15}$

\section{RESULTS AND DISCUSSIONS}

In a preliminary study of grafting induced by manganese(IV) various conditions were used to
(2) Dinitrophenylation. Dinitrophenylation was carried out by treating the wool fibers for several days with an ethanolic solution of dinitrofluorobenzene. ${ }^{13}$

\section{Grafting procedure}

Graftcopolymerization was carried out as follows.

A $50-\mathrm{m} l$ portion of acidified potassium permanganate $(1-4$ mmolar) at a specific temperature $\left(50,60\right.$, and $\left.70^{\circ} \mathrm{C}\right)$ was taken in a $100-\mathrm{m} l$ glass stoppered Erlenmayer flask. Wool sample $(0.5 \mathrm{~g})$ was introduced in the flask and the required amount of monomer was immediately added. The flask was stoppered and kept in a thermostat for varying periods $(15-129 \mathrm{~min})$; the wool was then extracted with acetone in a Soxhlet apparatus for $16 \mathrm{hr}$ to remove any adhering monomer or homopolymer and was then dried till constant weight was attained. The residual polymer was regarded as the grafted one.

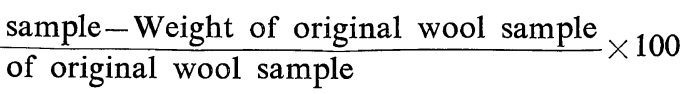

find those optimum conditions for grafting.

Variables studied were concentration of potassium permanganate, and methyl methacrylate, temperature, and reaction time.

\section{Initiator Concentration}

Figure 1 shows the effect of potassium permanganate concentration on the grafting of methyl methacrylate on wool fibers. It is

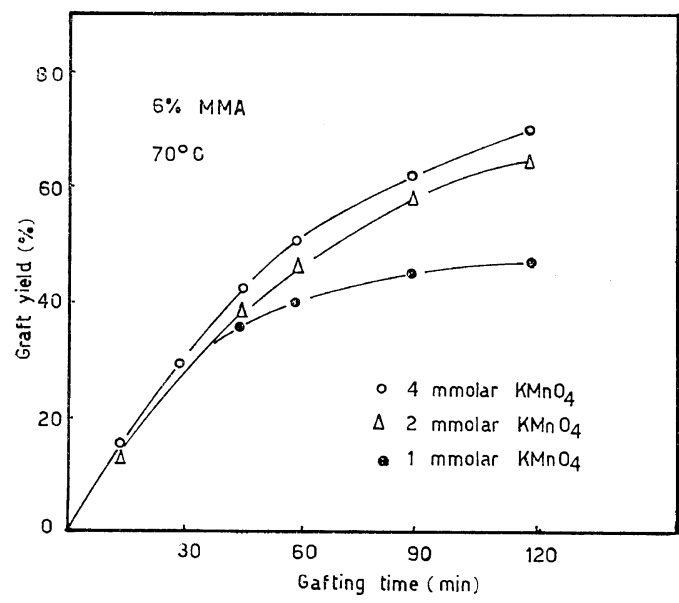

Figure 1. Effect of potassium permanganate concentration on graft yield. 
apparent that regardless of the concentration used, the grafting reaction is characterized by an initial fast rate followed by a slower one. It was also observed that most of the permanganate dioxide disappeared in the first few minutes of the reaction (see later). Furthermore, a substantial amount of homopolymer was formed during the grafting reaction. The homopolymerization was found to rely on the reaction time, temperature, and permanganate concentration; it was enhanced by increasing the magnitude of these parameters.

The rate of grafting at all the concentrations are the same in the early stages of the reaction, but the effect of potassium permanganate concentration is quite obvious in the later stages. The maximum graft yield obtained with a concentration of 1-mmolar potassium permanganate is significantly lower than that obtained with 2 or 4 mmolar within the range studied. However, 4 mmolar causes a slight increment in the maximum yield compared to 2 mmolar. This marginal difference suggests that during vinyl graft copolymerization of wool under the catalytic influence of potassium permanganate two reactions, namely grafting and oxidation, take place simultaneously. At concentration of $4 \mathrm{~m}$ molar potassium permanganate, the oxidation reaction seems to be more pronounced than the grafting reaction as compared with the same reaction when a concentration of 2-mmolar potassium permanganate was used. However, the greater amount of homopolymer formation when using higher potassium permanganate concentration, which adversely affect grafting, cannot be excluded.

\section{Monomer Concentration}

The effect of monomer concentration on grafting was evaluated in a series of polymerization in which three concentrations of monomers were used. As can be seen from Figure 2, increasing the monomer concentration from $4 \%$ to $6 \%$ caused a significant increment in the graft yield; a further increase caused but only a relatively small increase. This could be attributed to the limited solubility of the monomer in the reaction bath.

\section{Effect of Temperature}

The effect of raising the reaction temperature

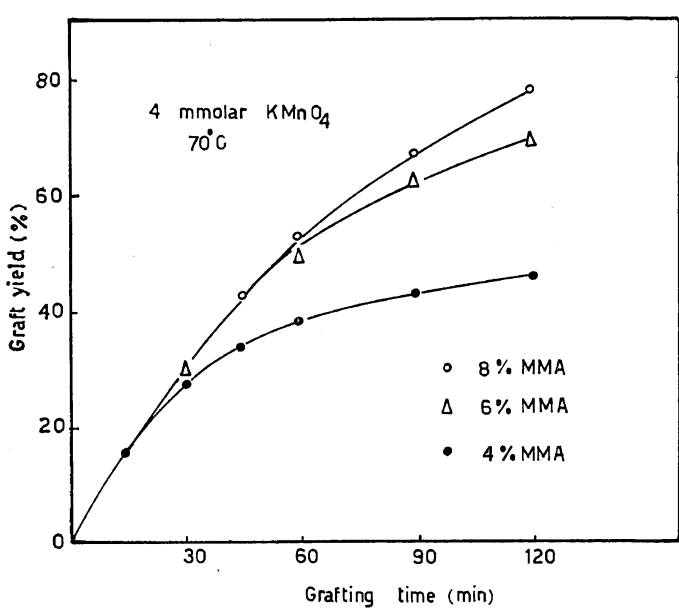

Figure 2. Effect of monomer concentration (MMA) on the graft yield.

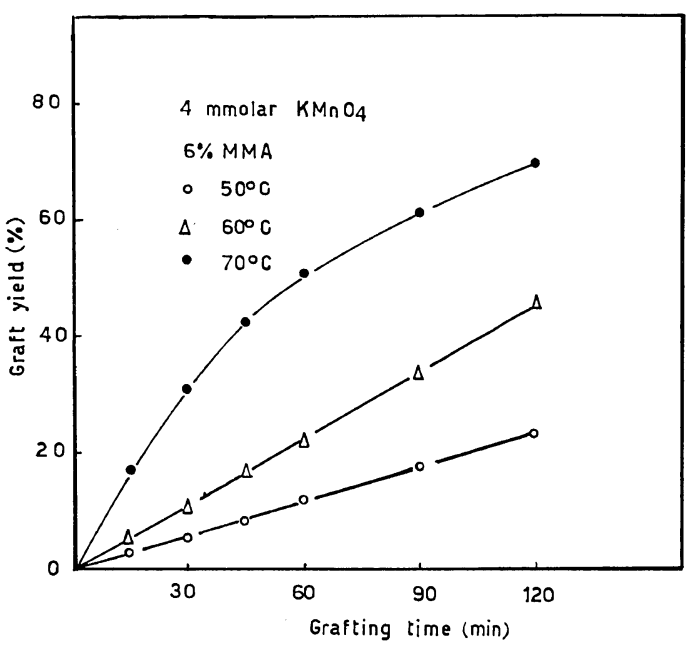

Figure 3. Effect of temperature on the graft yield.

is to bring about an outstanding increase in the rate of grafting (Figure 3). Increasing the temperature would be expected to cause: (a) increasing swellability of wool fiber, (b) increasing solubility of monomer, (c) enhancement in the rate of diffusion, (d) acceleration of the rate of manganese dioxide formation, and (e) increasing the rates of initiation and propagation of the graft. The net effect of all these leads to increased amount of graft formation. 


\section{A. Kantouch, S. Abdel-Fattah, and A. Hebeish}

\section{Reaction Time}

The influence of reaction time on the extent of grafting may be realized from Figures 1, 2, and 3 .

The grafting reaction took place without any induction period. It started very fast then becomes slower on prolonging the reaction time. This is due to a variety of reasons. There is a reduction in concentration of both monomer and initiator as the grafting reaction proceeds. Available sites on the wool backbone decreases the promotion of the possibility of grafting by increasing the contact time between wool and reagents. The grafted polymer may act as a barrier and inhibits diffusion of monomer and initiator for further grafting to occur.

\section{Permanganate Consumption}

Potassium permanganate consumed by wool in absence of monomer (i.e., oxidation) and during grafting at 50,60 , and $70^{\circ} \mathrm{C}$ are shown in Figure 4. It is clear that at the three temperatures studied, more than $60 \%$ of the permanganate was consumed during oxidation in the first $30 \mathrm{~min}$ of reaction time. Thereafter, however, the rate of permanganate consumption increases as the temperature increases perhaps due to the faster rate of formation and dissociation of the wool-permanganate complexes at higher temperatures.

The permanganate consumption during grafting, on the other hand, showed an extremely

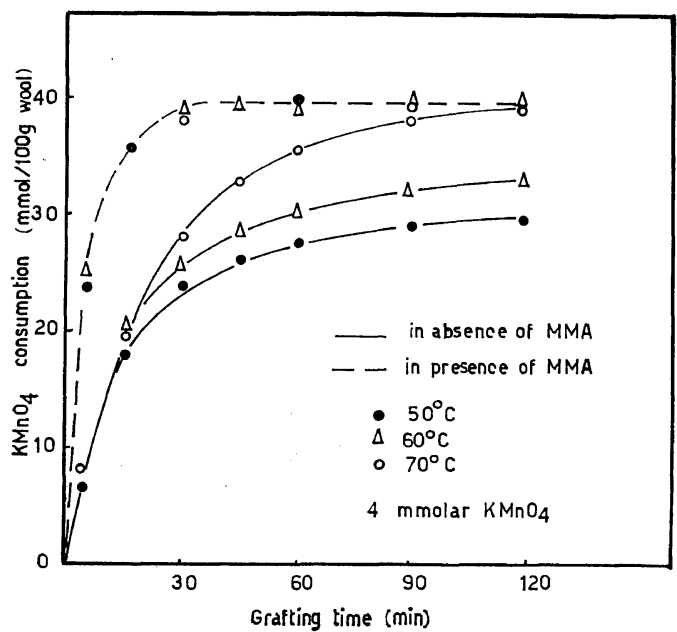

Figure 4. Potassium permanganate consumption during oxidation and grafting with MMA. fast initial rate and full consumption was attained in a relatively short time (Figure 4); the interaction of monomer with potassium permanganate accounts for this. Another interesting feature is that the comsumption during grafting is exceedingly higher than that during oxidation.

This could be due to initiation and termination of homoyolymer formation by the permanganate.

\section{Grafting on Modified Wools}

The influence of changing the physical and/or chemical structure of wool via reduction with thioglycollic acid (TGA) or by dinitrophenylation on the grafting reaction is shown in Table $I$. Data of the percent graft yield and permanganate consumption during oxidation and grafting of the untreated wool are also shown in the same table for comparison.

Treatment of wool with thioglycollic acid causes an increment in the thiol content (-SH group) of wool. Thus the higher graft yield of

Table I. Grafting of MMA onto modified woola

\begin{tabular}{|c|c|c|c|c|}
\hline & \multirow{2}{*}{$\begin{array}{c}\text { Time of } \\
\text { grafting, } \\
\text { min }\end{array}$} & \multirow{2}{*}{$\begin{array}{c}\text { Graft } \\
\text { yield, } \\
\%\end{array}$} & \multicolumn{2}{|c|}{$\begin{array}{l}\mathrm{KMnO}_{4} \text { consumption, } \\
\mathrm{mmol} / 100 \mathrm{~g} \text { wool }\end{array}$} \\
\hline & & & $\begin{array}{l}\text { In absence } \\
\text { of MMA }\end{array}$ & $\begin{array}{l}\text { In presence } \\
\text { of MMA }\end{array}$ \\
\hline \multirow[t]{6}{*}{ Wool } & 15 & 17.6 & 30 & 35 \\
\hline & 30 & 30.5 & 30 & 39 \\
\hline & 45 & 43.2 & 33 & 40 \\
\hline & 60 & 51.6 & 36 & 40 \\
\hline & 90 & 62.8 & 39 & 40 \\
\hline & 120 & 70.0 & 39 & 40 \\
\hline \multirow{6}{*}{$\begin{array}{c}\text { Reduced } \\
\text { wool }\end{array}$} & 15 & 80.6 & 29 & 32 \\
\hline & 30 & 118.0 & 30 & 34 \\
\hline & 45 & 138.0 & 32 & 40 \\
\hline & 60 & 146.0 & 33 & 40 \\
\hline & 90 & 180.0 & 35 & 40 \\
\hline & 120 & 180.0 & 36 & 40 \\
\hline \multirow{6}{*}{$\begin{array}{l}\text { Dinitro- } \\
\text { phenylated } \\
\text { wool }\end{array}$} & 15 & 2.1 & 22 & 30 \\
\hline & d 30 & 2.2 & 23 & 33 \\
\hline & 45 & 2.5 & 26 & 36 \\
\hline & 60 & 3.3 & 28 & 39 \\
\hline & 90 & 3.5 & 30 & 40 \\
\hline & 120 & 4.0 & 36 & 40 \\
\hline
\end{tabular}

a 3-mmolar $\mathrm{KMnO}_{4} ; \mathrm{pH} \mathrm{1;} \mathrm{6- \%} \mathrm{MMA;} \mathrm{liquor} \mathrm{ratio,}$ 100 ; temp, $70^{\circ} \mathrm{C}$. 
the reduced wool is unequivocally due to the presence of such groups in the wool molecules. This may suggest that the free radicals formed through abstraction of a hydrogen atoms from the $-\mathrm{SH}$ group are more efficient in inducing grafting than those probably formed by hydrogen abstraction from amino and hydroxyl groups. It is well known that thiol group has the ability to decompose the oxidizing agent and of participating in radical formation from the catalyst radical and in chain transfer from the growing homopolymer radicals. ${ }^{16}$ However, the increased swelling or accessibility of wool fibers by thioglycollic acid treatment cannot be ruled out.

Table I shows the percent graft yield and permanganate consumption during grafting and oxidation of dinitrophenylated wool. The graft yield and permanganate consumption of the said substrate is less than that of the untreated. The reason for this is that dinitrophenylation causes blocking of the free amino and hydroxyl groups in wool. Previous results from this laboratory ${ }^{6,8,10}$ have shown that these groups are the main sites for initiation of grafting on wool.

This may also be attributed to the bulkiness of the dinitrophenyl group and/or to the change of charges of wool fibers by dinitrophenylation. The negatively charged dinitrophenyl group may repell the similar ${ }^{1}$ charged MMA thereby decreasing the graft yield. An additional point of interest is that the rate of permanganate consumption during grafting of the dinitrophenylated wool is less than that of the untreated one (Table I). This is in agreement with previous reports ${ }^{17}$ indicating the role of the free amino groups in the oxidation process by increasing manganese dioxide adsorption.

\section{Tentative Mechanism}

It has been reported ${ }^{17}$ that the first step in oxidation of wool with potassium permanganate is adsorption of permanganate ions at specific sites on the wool molecules. The second step is the protolytic decomposition of the surface complex. Ionic oxidation-reduction process between manganese and permanganate ions then occurs with precipitation of manganese dioxide.

$$
2 \mathrm{MnO}_{4}^{-}+3 \mathrm{Mn}^{2+}+2 \mathrm{H}_{2} \mathrm{O} \longrightarrow 5 \mathrm{MnO}_{2}+4 \mathrm{H}^{+}
$$

This extremely rapid and complex process must proceed passing many stages to reach the final products.

Addition of vinyl monomers to potassium permanganate results in formation of manganese dioxide. This is in conformation with previous reports ${ }^{18}$ which showed also that addition of an acid to this mixture could affect polymerization. When oxalic acid was used, hydroxyl and carboxyl groups were found to be incorporated in the polymer. ${ }^{19}$

In the presence of wool fibers graftcopolymerization of the vinyl monomers takes place after creation of sufficient free radicals in the system as follows

$$
\begin{aligned}
& \mathrm{Mn}^{4+}+\mathrm{HNO}_{3} \rightleftharpoons \mathrm{Mn}^{3+}+\mathrm{NO}_{3}+\mathrm{H}^{+} \\
& \mathrm{Mn}^{3+}+\mathrm{H}_{2} \mathrm{O} \rightarrow\left[\mathrm{Mn}^{3+}(\mathrm{OH})^{-}\right]^{2+}+\mathrm{H}^{+} \\
& {\left[\mathrm{Mn}^{3+}\left(\mathrm{OH}^{-}\right)\right]^{2+} \rightleftharpoons \mathrm{Mn}^{2+}+\mathrm{OH}} \\
& \mathrm{NO}_{3}+\mathrm{H}_{2} \mathrm{O} \rightleftharpoons \mathrm{HNO}_{3}+\mathrm{OH} \\
& \mathrm{WH}+\mathrm{OH} . \rightarrow \mathrm{W} \quad+\mathrm{H}_{2} \mathrm{O}
\end{aligned}
$$

The formed free radical ( $\dot{W})$ may react with the vinyl monomer leading to graftcopolymer or may undergo another sequence of reaction leading to formation of wool oxidized products.

\section{Alkali Solubility}

The alkali solubility of grafted as well as potassium permanganate treated wool is shown in Table II.

The solubility of wool decreases significantly after grafting, whereas treatment of wool with potassium permanganate greatly increases the solubility. The reduction in the alkali solubility may be attributed to formation of some stable

Table II. Alkali solubility of oxidized and grafted woola

\begin{tabular}{ccrr}
\hline $\begin{array}{c}\text { Reaction } \\
\text { time, } \\
\text { min }\end{array}$ & $\begin{array}{c}\text { Graft } \\
\text { yield, } \\
\%\end{array}$ & \multicolumn{2}{c}{ Alkali solubility, \% } \\
\cline { 3 - 4 } & Grafted & Oxidized \\
\hline Untreated wool & 0.00 & 10.87 & 10.87 \\
15 & 17.60 & 3.84 & 28.00 \\
30 & 30.00 & 3.46 & 32.40 \\
45 & 43.20 & 2.73 & 36.00 \\
60 & 51.60 & 1.64 & 48.80 \\
90 & 62.80 & 1.35 & 64.90 \\
120 & 70.00 & 1.21 & 84.40 \\
\hline
\end{tabular}

a 4-mmolar potassium permanganate, 6-\% MMA; liquor ratio, 100 ; temp, $70^{\circ} \mathrm{C}$. 


\section{A. Kantouch, S. Abdel-Fattah, and A. Hebeish}

Table III. Acid hydrolysis and cystine content of grafted woola

\begin{tabular}{cccccccc}
\hline $\begin{array}{c}\text { Reaction } \\
\text { time, } \\
\text { min }\end{array}$ & $\begin{array}{c}\text { Graft } \\
\text { yield, } \\
\%\end{array}$ & $\begin{array}{c}\text { Dry wool } \\
\text { sample, } \\
\text { mg }\end{array}$ & $\begin{array}{c}\text { Weight of } \\
\text { wool part } \\
\text { in the } \\
\text { sample, mg }\end{array}$ & $\begin{array}{c}\text { Weight of } \\
\text { hydrolyzed } \\
\text { woollen } \\
\text { fraction, mg }\end{array}$ & $\begin{array}{c}\text { Fraction of } \\
\text { hydrolyzed } \\
\text { woolb, } \%\end{array}$ & $\begin{array}{c}\text { Cystine } \\
\text { content of } \\
\text { hydrolyzed } \\
\text { part, \% }\end{array}$ & $\begin{array}{c}\text { Cystine } \\
\text { content of } \\
\text { permanganate } \\
\text { treated wool, } \%\end{array}$ \\
\hline 0 & 0 & 0 & 0 & 0 & 0 & 0 & 13.00 \\
15 & 17.6 & 100 & 85 & 47.2 & 55.5 & 10 & 12.70 \\
30 & 30.0 & 100 & 81.2 & 45.0 & 55.5 & 8 & 12.20 \\
45 & 43.2 & 100 & 69.5 & 44.5 & 64.0 & 7.5 & 11.70 \\
60 & 51.6 & 100 & 65.8 & 43.5 & 65.8 & 7.0 & 11.50 \\
90 & 62.8 & 100 & 61.3 & 40.0 & 65.1 & 6.5 & 10.50 \\
\hline
\end{tabular}

a 4-mmolar potassium permanganate; 6-\% MMA; liquor ratio, 100 ; temp, $70^{\circ} \mathrm{C}$.

b Based on the woollen fraction of the sample.

crosslinks in wool via termination of grafted growing chains by coupling. The significant difference between the solubility of grafted and permanganate-treated wool may also be due to resistance of the former to the oxidizing action of permanganate. The permanganate treatment is also reflected on the cystine content of wool and this may be one of the reasons for the increase in its alkali solubility.

\section{Acid Hydrolysis}

Grafted wool highly resisted acid hydrolysis; $24 \mathrm{hr}$ hydrolysis using 6- $N \mathrm{HCl}$ in sealed tube at $115^{\circ} \mathrm{C}$ resulted in partial hydrolysis of the sample (Table III). The hydrolyzed fraction amounted only to $55-65 \%$ of the woollen part of the grafted sample. It was also observed that this fraction increased on increasing the graft yield. This suggests that part of the free radicals formed on the wool backbone are captured by the monomer, while another part proceeds to oxidation of wool. This is substantiated by the fact that the cystine content of the soluble part decreases by increasing grafting time (Table III). However, the decrease in the cystine content of the solubilized part of the grafted wool is greater than that of permanganate-treated wool and suggests the resistance of some cystine residues to acid hydrolysis. Cystine residues in wool may be one of the important centres for grafting. On hydrolysis, such residues remain captured at the end of the insoluble graftcopolymer and do not diffuse in solution.

\section{REFERENCES}

1. V. Stannett, K. Araki, J. A. Cervasi, and
S. W. Mcleskey, J. Polym. Sci., Part A, 3, 3763 (1965).

2. H. Ishibashi and M. Oka, Preprint, International Wool Textile Research Conference, Paris, 1965, Section III, p 385.

3. H. X. Needles and W. L. Wasley, Text. Res. J., 37, 97 (1967).

4. M. Negishi, K. Arai, and S. Okada, J. Appl. Polym. Sci., 11, 2427 (1967).

5. L. Valentine, J. Text. Inst., 46, 270 (1955).

6. A. Kantouch. A. Hebeish, and A. Bendak, Eur. Polym. J., 7, 153 (1971).

7. A. Bendak, A. Hebeish, and A. Kantouch, Kolorisztikai Ertesito, 13, 106 (1971).

8. A. Kantouch, A. Hebeish, and A. Bendak, Text. Res. J., 42, 7 (1972).

9. W. S. Simpson and W. Van Peit, J. Text. Inst., 57, 493 (1966).

10. A. Hebeish, A. Bendak, and A. Kantouch, $J$. Appl. Polym. Sci., 15, 2733 (1971).

11. T. Rainer and U. Egon, Ger (east) Patent 61532, 5 May, 1968.

12. U. Egon and T. Rainer, Faser Forsch. Textiltech., 20, 451 (1969).

13. W. R. Middlebrook, Biochem. Biophys. Acta, 7, 547 (1951).

14. M. Harris and A. Smith, Amer. Dyest. Repts., 25, 542 (1955).

15. K. Shinohara, J. Biol. Sci., 109, 665 (1935); H. Zahn and K. Traumann, Melliand Textilber., 15, 1069 (1954).

16. M. Negishi and K. Arai, J. Appl. Polym. Sci., 11, 115 (1967).

17. P. Alexander, D. Carter, and R. F. Hudson, J. Soc. Dyers Colour, 65, 152 (1949).

18. S. R. Palit and R. S. Konar, J. Polym. Sci., 57, 609 (1962); 58, 85 (1962).

19. R. Mitra, A. R. Mukherjes, and S. R. Palit, Indian J. Chem., 3, 49 (1965). 